\title{
PIRILAMPO, LAMPARINA: LUMEZINHO DE MIM, CÉU PINTADO DE HISTÓRIA
}

- ROSVITA KOLB BERNARDES

https://orcid.org/0000-0001-9090-4633

Universidade Federal de Minas Gerais

RESUMO Esse texto apresenta algumas histórias da minha infância, vividas no Rio Grande do Sul, no extremo sul do Brasil, e que me compõem como aprendiz ao longo da vida. Para dar forma e sentido a essa experiência inspiro-me no "ateliê biográfico de projeto", tal qual formulado por Delory-Momberger (2006). Movida pela certeza de que é preciso fazer conhecer-se a si mesmo para conhecer o outro, chego através da pesquisa autobiográfica, feitura que começou durante o meu doutorado, à minha prática como professora, artista e pesquisadora.

Palavras-chave: Narrativas autobiográficas. Memória de infância. Arte e docência.

\section{ABSTRACT FIREFLY, LAMP: A TINY BRIGHT OF ME, A SKY PAINTED OF HISTORY}

This text presents some stories from my childhood, lived in Rio Grande do Sul, in the extreme south of Brazil, which compose me as an apprentice throughout life. To give shape and meaning to this experience I draw inspiration from the "biographical project studio", as formulated by Delory-Momberger (2006). Moved by the certainty that it is necessary to get to know oneself to know the other, I arrive through the autobiographical research, work that began during my doctorate, to my practice as a teacher, artist and researcher.

Keywords: Autobiographical narratives. Childhood memory. Art and teaching.

\section{RESUMEN LUCIÉRNAGA, LÁMPARA: POCA LUZ MÍA, CIELO}

\section{PINTADO DE HISTORIA}

Este texto presenta algunas historias de mi infancia vividas en Rio Grande do Sul, en el extremo sur de Brasil, que me componen como aprendiz durante toda la vida. Para dar forma y significado a esta experiencia, me inspiro en el "estudio de diseño", formulado por Delory-Momberger (2006). Movida por la certeza de que es necesario conocerse a sí mismo para conocer al otro, llego a través de la inves- 
tigación autobiográfica, trabajo que comenzó durante mi doctorado, a mi práctica como profesora, artista e investigadora.

Palabras clave: Narraciones autobiográficas. Recuerdo de la infancia. Arte y enseñanza.

O escuro encosta neles para ter vaga-lume. Manoel de Barros (2003)

\section{Lume que vaga. Redoma de luz Lamparina}

Comecei assim. Tateando os pontinhos de luz de minha própria história: vida vivida! Fiz como o poeta, encostei no escuro para ter vaga-lumes e acordei na minha infância rodeada deles na mata atlântica, quintal da casa de minha avó Oma ${ }^{1}$ Rosa, onde vivi dias de vaga-lumes e de Lamparina. Entro no movimento de rememorar, de desenhar a linha novelo multicor de minha própria história de vida. Não sei se percorro fins ou começos porque já não sei se, ao lembrar, não tenho esquecimentos e se a linearidade é só uma saudade preenchida de data. Sigo segurando a ponta da linha sem receio de embolar, cair ou saltar. Sigo o caminho de esquecer para acender a chama de lembrar. Meu pequenino pedaço de história que aqui narro começa com lumezinhos flutuantes: vaga-lumes e a lamparina de minha Oma Rosa.

Tenho os cabelos amarelos quase sol, os olhos azuis de claro céu e a pele branca muito fininha. $\mathrm{Na}$ brasilidade de meu sangue tenho os inícios vindos de outros oceanos. Do grande navio, guardei três baús, que guardados segredos de histórias trouxeram. Eu: sou entre Brasil e Alemanha, um fruto.

Em 1930 meus avós, oriundos da região de Baden-Württemberg, na Alemanha, desembarcaram no sul do Brasil. Primeiro no pequeno povoado de Palmitos, depois seguiram para outro povoado que hoje chama-se São Vendelino e depois para cidade de Nova Pe-

1 Oma é a forma cotidiana e carinhosa de avó em alemão. Opa é a forma masculina. trópolis, onde começa uma parte de minha história de vida e formação. Meus avós paternos se conheceram muito jovens, no tempo em que se namorava no banco da igreja e no portão de casa.

Figura 1: Oma Rosa e eu

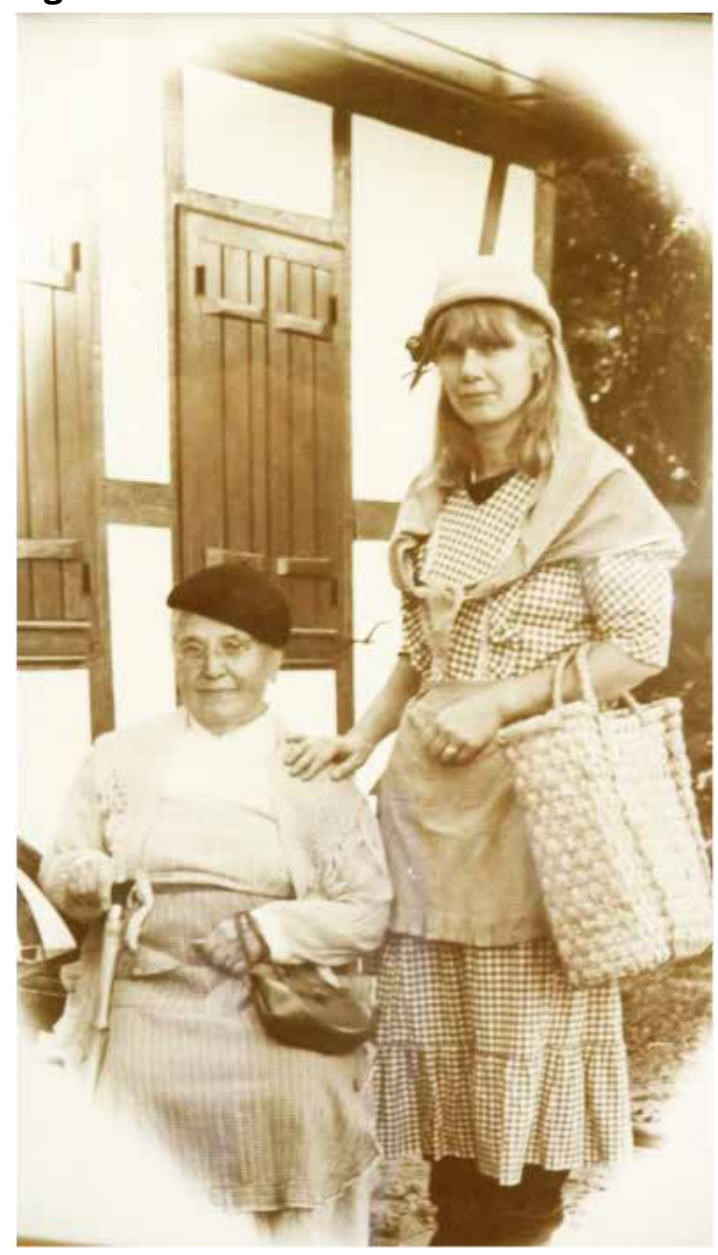

Fonte: Acervo pessoal

A avó, Oma Rosa, jovem bonita de olhos azuis, tinha um jeito cativante de ser com uma estatura forte com passos curtos. Se apaixonou pelo meu Opa Josef. Um jovem es- 
tudante de teologia, futuro pastor da igreja Luterana no Brasil. Rapaz alto, grande, forte, corajoso e decidido na sua missão de querer ajudar os outros. Não sei o que aconteceu entre eles, mas acho que foi amor à primei- ra vista. Só sei que em pouco tempo a Oma Rosa casou-se e foi embora para o Brasil com o meu Opa Josef que tinha a assumido a tarefa na sua missão pastoral de fazer um estágio no Brasil.

Figura 2: Oma Rosa, Opa Josef, meus tios e meu pai

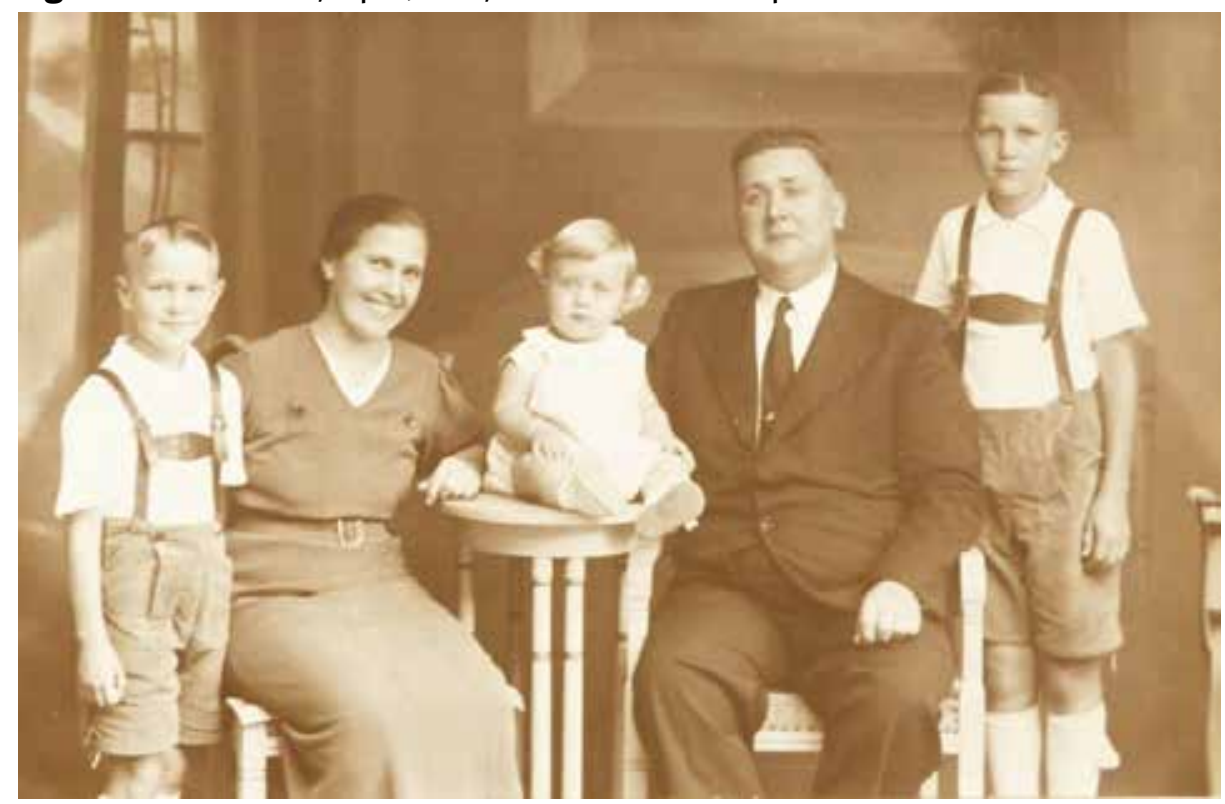

Fonte: Acervo pessoal

Assim chegaram ao porto de Santos e depois a Porto Alegre. Fazia parte dessa jornada instalarem-se em um pequeno povoado para acolher os membros da igreja. Muito tempo depois, já adulta, soube de algumas histórias contadas pela Oma Rosa deste início de vida aqui no Brasil.

Na sua bagagem tinha apenas o necessário para iniciar a nova vida. No povoado Palmitos, onde chegaram por primeiro, um pedaço da escola foi transformado em quarto para recebê-los.

Figura 3: Roupas sobre o baú de meu Opa Josef

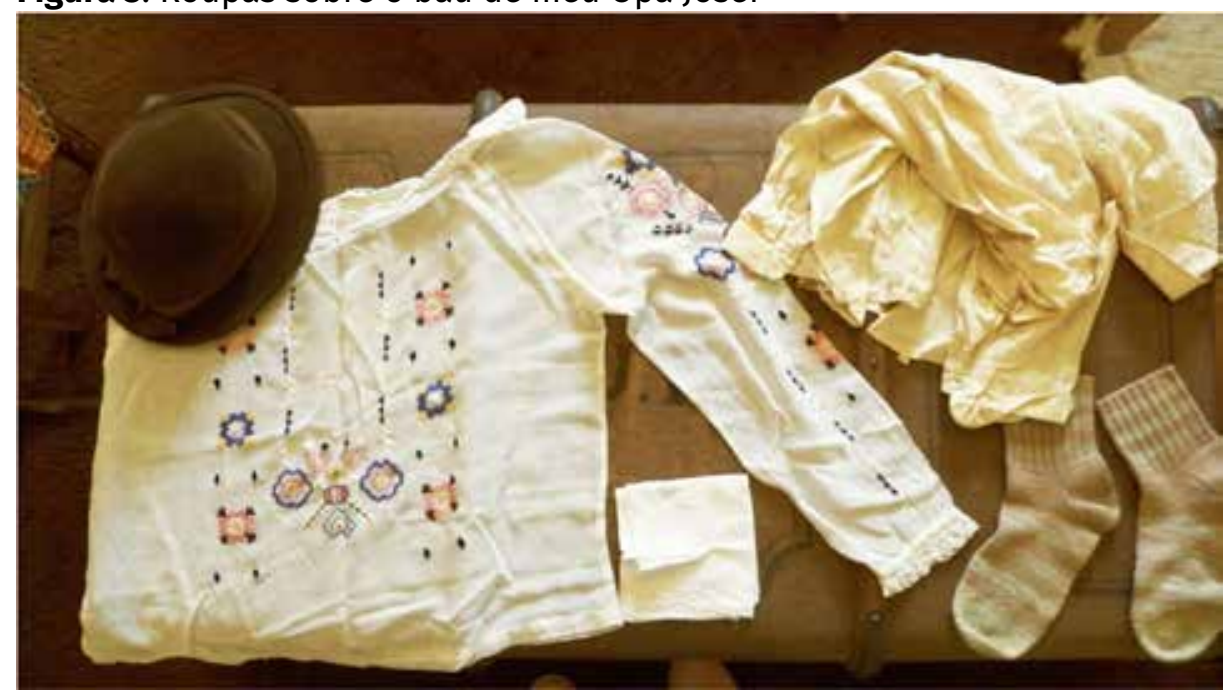

Fonte: Acervo pessoal 
Colchão para dormir não existia e lugar para comprar muito menos ainda. Assim, enquanto esperavam a bagagem chegar, dormiram no chão da escola. Seu novo lar em terras brasileiras.

Sou neta da Oma Rosa e do Opa Josef. A terceira geração da família Kolb no Brasil. Foi no convívio com eles que descobri a força e energia que pode ter a meditação e a oração.

Meu avô foi um homem religioso. Tudo era um fator de agradecimento. Desde a comida, os filhos, as noras, netos, amigos e parentes na Alemanha. Era uma reza espontânea, intuitiva. Era por meio das orações que o Opa Josef estabelecia vínculos com o exterior, citando nome por nome de todos os familiares. Criamos, assim, uma consciência das nossas raízes familiares.

\section{No encontro com as histórias de vida do outro}

Há alguns anos o encontro com as histórias de vida vem alimentando minha trajetória como professora-artista em meu cotidiano. Hoje já não sei mais dizer quando é um ou outro. Como prática em minhas disciplinas para os alunos da licenciatura em Artes da Escola de Belas Artes da UFMG, começo sensibilizando para a escuta e o exercício de rememorar. Falar de si. Contar sua história. Ouvir a história do outro.

Nesse balanço entre fala e escuta me alimento profundamente das histórias de meus alunos. Me alimento dos seus trabalhos autobiográficos, da sua intimidade, criatividade, sua produção estética e plástica sob a luz da arte. Configura-se a partir desse momento um potente arsenal, quando um se torna objeto da sua própria pesquisa, onde a experiência de rever, rememorar, lembrar e narrar vai se construindo em um caminho ziguezagueante, que pisca-pisca no escuro, lumiando ora aqui, ora acolá.
Assim, venho há tempos ensaiando olhar, rememorar, iluminar minha própria história para fazer dela meu objeto de pesquisa e investigação. Iniciei esse processo durante 0 meu doutorado, quando percebi a importância do estudo das histórias de vida como possibilidades de se compreender os caminhos percorridos durante o desenvolvimento dos saberes escolares. (SOUZA, 2006) O sujeito aprende a partir da sua própria história e, ao narrá-la, permite-se um espaço para pensar e sentir sobre si e sobre os outros.

Foi o tempo do doutorado que me deu tecido, fio e linha para mergulhar no campo da autobiografia como espaço de reflexão e diálogo sobre as minhas aulas na graduação, pósgraduação e cursos de formação continuada de professores. Espaço que me possibilitou, de acordo com a pesquisa autobiográfica, rever também o meu próprio percurso artístico docente, onde a dimensão temporal e a narrativa de vida são constitutivas da experiência humana.

Recentemente, ao assistir ao filme Walachai (ZILLES, 2013), sobre uma pequena comunidade rural no sul do Brasil, onde se fala um antigo dialeto alemão, voltei com toda a força à minha memória de infância. Rejane Zilles não só conta a história dessa pequena comunidade, mas a história de Walachai lhe pertence. Ela viveu nesse lugar até os 9 anos de idade. A história do filme de alguma forma também me pertencia.

Carrego comigo da infância o não saber falar português até os 8 anos de idade e de ser alfabetizada em alemão. De chegar na escola do Ensino Fundamental e não entender nem o que a professora falava e muito menos os meus colegas de classe. Falar com sotaque, trocar as vogais. Caminhei um tempo aqui e acolá. Entre lugares, entre pausas e silêncios para ouvir, escutar e olhar para saber quem eram os meus pares. 
Talvez esse tenha sido um momento em que meu coração piscou como pisca um vaga -lume à procura dos seus. Dali iniciei um processo profundo de fazer nascer coragem para ver, lembrar e narrar sobre mim e minha história de vida.

\section{Fazer nascer coragem para ver, lembrar e narrar: as cartas}

Inspirada nas histórias de infância de Benja- min (1987) busco por outras historietas do meu cotidiano. São histórias que, por meio da ação de lembrar, são revisitadas e ressignificadas por mim. Comecei a fazer vários movimentos de busca por indícios na minha casa pela minha história. Em um destes movimentos, obstinadamente à procura de uma carta de minha avó em que falava sobre a prisão de meu avô, em 1940, quando Getúlio Vargas proibiu falar e ler em alemã, encontrei em um saquinho de plástico fotos, bilhetes e cartas.

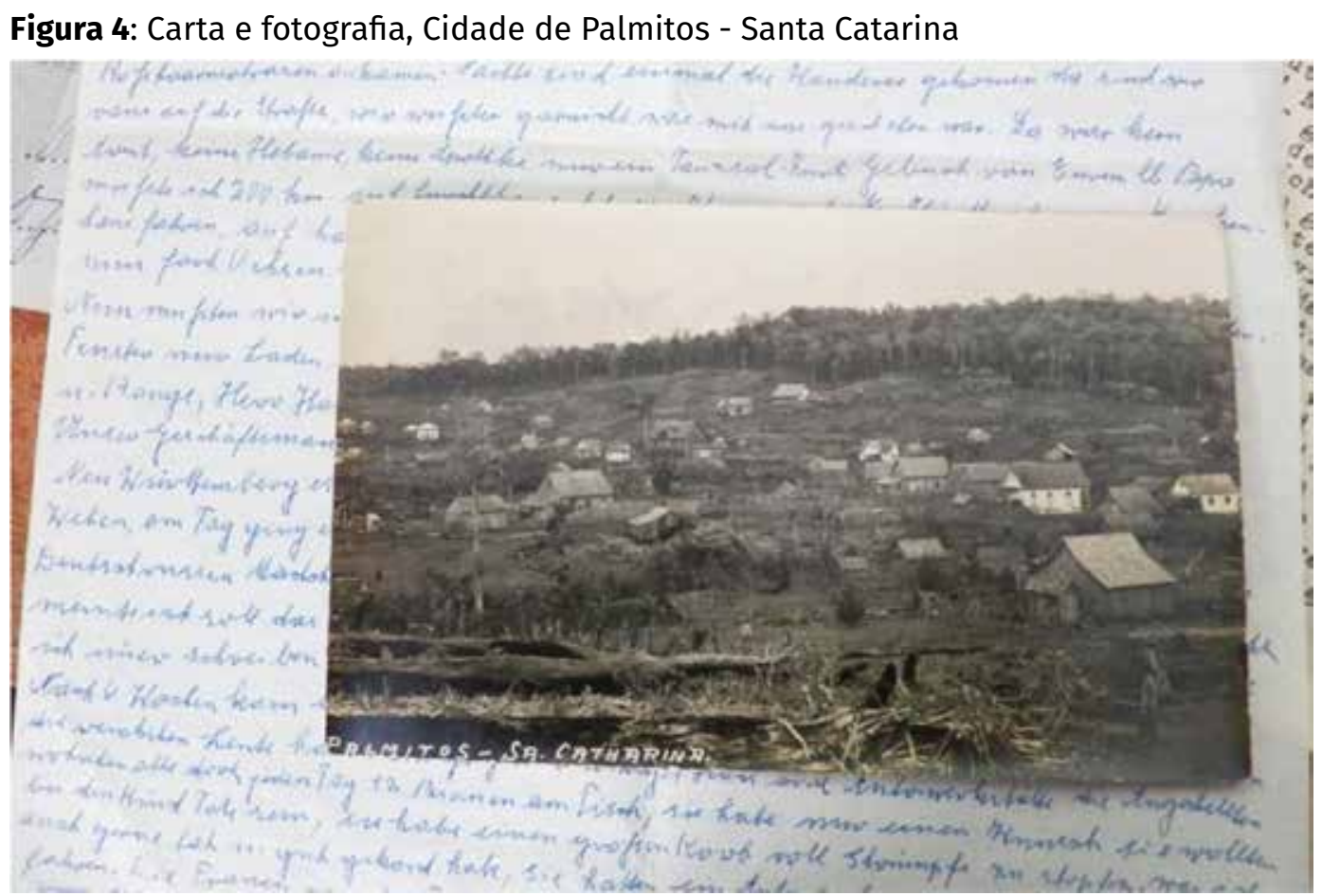

Fonte: Acervo Pessoal

Abro e leio duas cartas escritas pelo meu avô para os meus aniversários de 9 e de 14 anos de idade e uma outra carta escrita pela minha avó no dia 27 de novembro de 1981, narrando sobre a lamparina da sua casa.

Hoje, ao escrever esse texto, volta não só à minha memória de infância a lamparina, pela qual tenho um fascínio especial, mas as cartas escritas por meu avô no dia do aniversário. São objetos revisitados pelos espaços percorridos no tempo de infância onde personagens e pessoas marcaram um tempo vivido. Encontrar com as cartas, fotos, bilhetes, lamparina, constitui o que Delory-Momberger (2012, p. 75) chama de mundo interior do espaço exterior. Para ela:

Essas construções biográficas do espaço levamnos a elaborar um mundo de significações e valores que constitui, de alguma maneira, para nós, o mundo interior do espaço exterior. É sob o prisma desse mundo interior, que o espaço exterior vai se achar dotado, para que cada um de nós, de uma biograficidade singular, isto é de uma capacidade de construir vestígio, de construir experiência, de fazer sentido em nossa existência.

Olho as fotos e releio as cartas, escritas em 
um tom amoroso, cheias de múltiplos sentidos. São enviadas e recebidas para celebrar a vida. Abro e leio:

Hoje ao celebrarmos os seus nove anos de idade me lembro quando perdi o meu pai aos nove anos. Tinha mais oito irmãos menores do que eu. Tive que ajudar a sua bisavó, a minha mãe, com tudo. Se não teríamos morrido de fome. Aprendi com isto que com nove anos já podemos ajudar os nossos pais nos afazeres da casa. (KOLB, 1964)

Em outra carta, quando faço 14 anos, ele me conta que com essa idade os jovens na Alemanha finalizam um ciclo na escola e que alguns seguem seus estudos e outros vão para escolas mais técnicas. E que aos 14 anos de idade se iniciaria uma nova fase na minha vida, quando se é convidada a participar do ensino confirmatório na igreja Luterana e onde vai celebrar diante de uma comunidade a sua entrada para o mundo adulto. Ele segue na sua escrita e diz:

É em tudo isto que estamos pensando hoje no seu aniversário de 14 anos como a nossa neta mais velha. Você com certeza vai perceber quando a fase da infância se encerra e inicia-se a fase da juventude. Te desejamos de coração, alma e corpo um novo tempo de vida. (KOLB, 1969)

Figura 5: Minha fotografia de infância

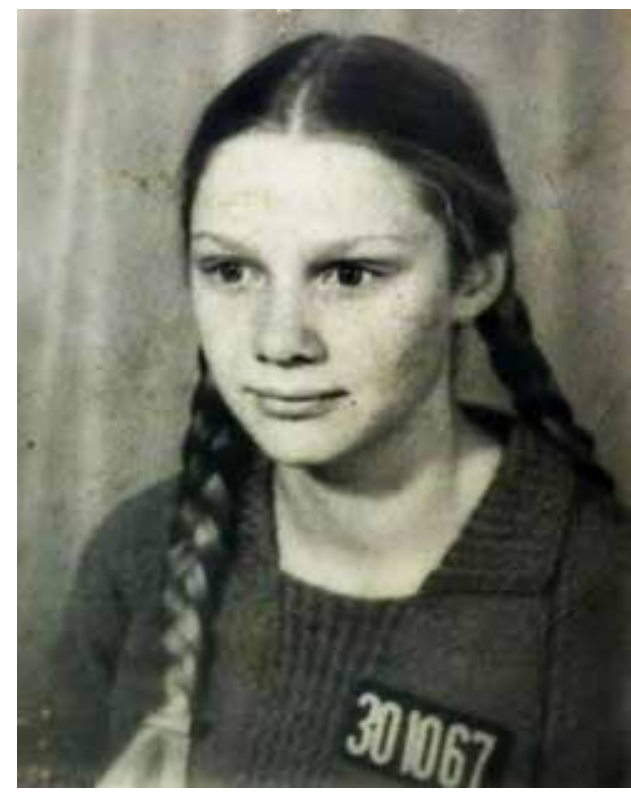

Fonte: Acervo Pessoal
Ao reler essas cartas me invade um sentimento de amor anunciado por mim, como o pisca pisca do vaga-lume à procura dos seus. Recolho um jeito simples de escrever, onde pensamentos são carregados de vida de um amor de avós presentes. Sempre!

São cartas que revelam uma concepção de educação que passa pelo conceito de cuidado, zelo com o outro, um olhar humanista presente. Um olhar que olha para a infância, para a juventude. Nas entrelinhas das cartas leio uma postura que indica valores que passam pelo respeito aos mais velhos, aos pais como autoridade, uma postura de escuta, de silêncio, de cuidado com o outro, obediência, respeito e humildade. Uma memória.

Antigamente também escrevia cartas. Escrevia para contar a vida. Escrevia para viajar para encontrar. Hoje já não escrevo mais cartas.

Ao reler as cartas escritas dos meus avós, vêm à minha mente lugares objetos familiares que fazem parte do espaço doméstico, a minha intimidade. Tenho com esses lugares e objetos da minha infância uma relação de construção biográfica recíproca: eu os constituo e eles me constituem. São formas de manifestações de nós mesmos.

São objetos que fazem parte de um espaço memória-infância no qual me reconheço e no qual também sou reconhecida pelo outro. Ao pensar na força e potência que o objeto carta pode ter, me vem à mente o trabalho contemporâneo da artista Elisa Macedo com as suas cartas visuais. Ela destaca que:

Cada carta que chegava em casa já me enchia os olhos. Saber notícias dos amigos, da família, receber foto de um lugar distante. Era todo um ritual de enlaces. Até o aparato para cerrar a ponta dos envelopes sem "machucá-lo" tínhamos. A carta é uma memória. Minha memória granular. Nas aulas de redação na escola, era a partir das cartas que me encontrava com os esmeros da caligrafia e do contar. Mais tarde 
soube das cartas importantes que mudaram a vida da minha mãe, as cartas para os amigos que só encontravam este meio para contar vida. Viajei para diferentes paisagens e as cartas eram deixadas antes da partida e escritas nos percursos. Escrevi cartas sem nem ir, para contar para alguém como ficou a vida aqui enquanto a ausência existia, ainda que temporária. Escrever sempre foi uma possibilidade terna. Filmar foi o encontro com a textura, o encontro com o olhar do meu com o outro, o respeito pelas histórias que começavam a existir dentro. A cada nova passagem, o desejo de remeter sobre as paisagens, primeiro entendendo a geografia, o espaço, o som, a vida para ser poesia. (MACEDO, 2016, p. 1).

Assim como me toca profundamente o trabalho dessa artista, sinto também o meu coração redondo quando leio as muitas histórias escritas nos cartões-postais entre João Guimarães Rosa e suas netas (ROSA, 2003). 0 livro "Quando eu voltei, tive uma surpresa", de Joel Rufino Santos (2000), escrito durante a sua prisão durante a ditadura, em 1972, para seu filho, e o livro "Correspondência" de Bartolomeu Campos de Queiroz (2004) me remetem a outros sentidos formas de vida e significação de pensamento.

Tem dias que procuro por respostas de um tempo vivido e que se esconde em minhas gavetas, cadernos de professora, bilhetes escritos, derramados em bordas de livros e fotos. Cartas. Envelopes lacrados e rompidos pelo destinatário. Fotos e lamparina. Lembranças concretas de um certo tempo da minha vida, de um encontro, de um certo acontecimento de minha existência. Dia de lamparina.

\section{Dia de Lamparina: redoma de luz}

Contar, escrever e falar sobre si, sobre a sua história vivida é uma possibilidade de interagirmos, inter-relacionarmos para refazer caminhos, recompor rastros para poder recontar a nossa história.
Figura 6: A lamparina de minha avó

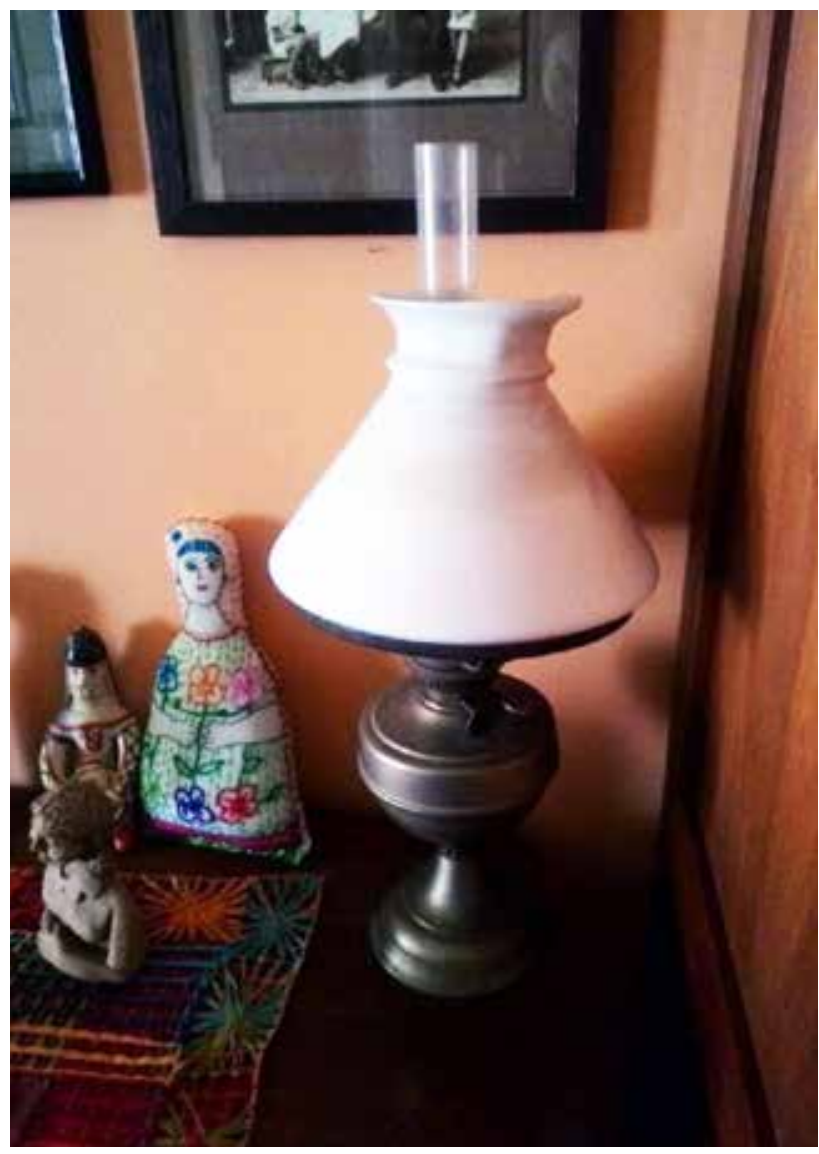

Fonte: Acervo pessoal

Pela ação de rememorar apontada por Walter Benjamin (1987) sigo ziguezagueando entre passado e presente com a intenção de trazer o passado com o olhar do presente. Assim, vou em busca de querer saber onde ficou a lamparina da casa da minha Oma Rosa. Objeto de memória da minha infância que carrega a promessa de luz. Arde ao meu tato, queima e me fascina para quebrar o escuro da noite. Redoma é sua luz.

Leio a carta da Oma Rosa contando sobre a importância da lamparina na sua vida:

Quando eu estava grávida do seu pai tive que sair do povoado de Palmitos bem antes dele nascer, pois lá não tinha parteira, nem hospital. Resolvi sair alguns dias antes quando apareceram as primeiras dores do parto. E assim fui com um vizinho, Seu Haas de carro em uma estrada de chão, cheia de buracos para um outro lugarejo que ficava a $200 \mathrm{~km}$ dali. No meio do caminho, o carro atolou e ficamos parados 
no meio da estrada no escuro. A sorte foi que eu tinha levado a lamparina e assim com ajuda de alguns moradores conseguimos tirar o carro puxado por alguns bois. A minha tarefa naquela noite foi além de segurar a minha barriga no nono mês de gravidez, iluminar a estrada. A lamparina foi sempre um objeto muito importante para nós. (KOLB, 1988)

Segue narrando que se lembra que, já morando no povoado de São Vendelino/RS, a luz era fornecida para as casas por um gerador que funcionava até as 10 horas da noite. Depois só com a lamparina para ler ou fazer algo à noite.

Hoje, ao reler essa carta, procuro por imagens. Imagens da infância que revisitam a minha memória. São imagens de uma criança de seis anos de idade que passava sozinha as férias na casa dos avós. Entre as sombras, frestas e luzes que piscavam aqui e acolá, os vaga-lumes, pirilampos, a lamparina me guiavam.

Seguia o seu rastro. Seu feixe de luz. Era pela mão da minha avó que ela era levada para cá e para lá. Para frente e para trás. Parecia uma dança. Uma dança que alumiou meu tempo de criança.

Venho já algum tempo trabalhando com as histórias de vida dos meus alunos nos cursos de graduação. Hoje, ao repensar sobre o que tenho feito, escrito, dito sobre a minha história e também dos meus alunos em sala de aula, não tenho dúvidas que acessar a memória e biografar-se, carrega a essencialidade do poder de as pessoas se reconhecerem como sujeitos de suas próprias histórias. É encontrar-se com uma maneira singular de produzir escrita e reflexão. É retomar a experiência do espaço, dos objetos, dos sentidos do vivido. É retomar as imagens e significância do que foi desenvolvido ao longo da nossa história pessoal.
Destaco que ao refletir sobre o meu processo de formação, ao trazer as cartas que compartilho aqui, ilumino saberes que me constituíram como pessoa e que me ajudam a dar visibilidade aos fios de histórias particulares e que se entrelaçam em trajetórias reveladas no presente como professora artista. Então, no momento que trago uma visão de mundo focado pela lente da memória da infância, penso que vou construindo e elaborando experiências vividas que me permitem ir além dos fatos vividos e registrados no papel. Nesse trajeto de volta para si e encontrar-se com a sua própria história inspiro-me no "ateliê biográfico de projeto", que é compreendido como

[...] um processo que inscreve a história de vida em uma dinâmica prospectiva que lida o passado, o presente e o futuro do sujeito e visa emergir o seu projeto pessoal, considerando a dimensão do relato como construção da experiência do sujeito e da história de vida como espaço de mudança aberto ao projeto de si. (DELORY-MOMBERGER, 2006, p. 359)

Dinâmica bastante propícia para lançar luzes sobre aquelas texturas da vida que compõem os percursos pessoais, revelando histórias que só se deixam mostrar por meio das narrativas que engendram o pensar sobre si e a tomada de consciência de si. Assim, sigo em busca de narrar o vivido em meio a um emaranhado de fios que vão compondo a minha trama vida para reconhecer-me como sujeito da minha própria história, atribuindo sentido aos diferentes itinerários percorridos até aqui.

Acessar as cartas, as fotos, a minha memória, é encontrar com a minha própria voz, com o mundo que rodeou a minha infância. São histórias, vestígios que me permitem compreender um pouco o que sou hoje como professora e artista. Olho para o céu pintado de histórias. 
Figura 7: Carta escrita por meus avós

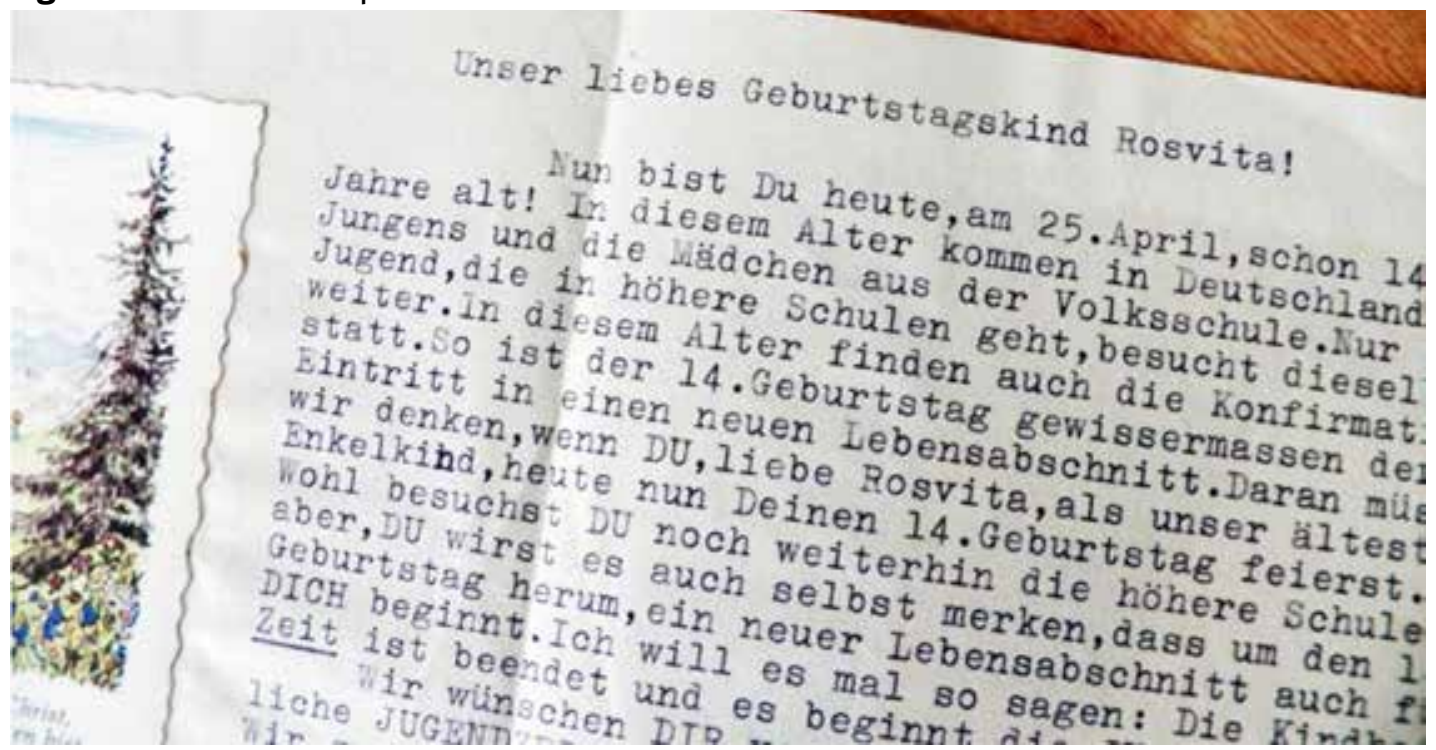

Fonte: Acervo pessoal

\section{Referências}

BARROS, Manoel de. Memórias inventadas: a infância. São Paulo: Planeta, 2003.

BENJAMIM, Walter. Rua de mão única. 4. ed. São Paulo: Brasiliense, 1987.

DELORY-MOMBERGER, Christine. A condição biográfica: ensaios sobre a narrativa de si na modernidade avançada. Natal: EDFRN, 2012.

DELORY-MOMBERGER, Christine. Formação e socialização: os ateliês biográficos de projeto. Educação e Pesquisa. São Paulo, v. 32, n. 2, p. 359-371, ago., 2006. Disponivel em: http://www.scielo.br/scielo. php?pid=S1517-97022006000200011\&script=sci_abstract\&tlng=pt Acessado em: 2 set 2019.

KOLB, Josef. Correspondência privada. Nova Petrópolis: 1964.

KOLB, Josef. Correspondência privada. Nova Petrópolis: 1969.

KOLB, Rosa. Correspondência privada. São Leopoldo: 1988.

MACEDO, Elisa. Cartas Visuais, 2016. Idealização.
Disponível em: http://cartasvisuais.com.br/idealizacao/. Acesso em: 26 mar. 2020.

QUEIRÓS, Bartolomeu Campos de. Correspondência. Belo Horizonte: RHJ, 2004.

ROSA, João Guimarães. Ooó do Vovô!: correspondência de João Guimarães Rosa, vovô Joãozinho, com Vera e Beatriz Helena Tess: de setembro de 1966 a novembro de 1967. São Paulo: Edusp; Belo Horizonte: Editora PUC Minas; Imprensa Oficial do Estado de São Paulo, 2003.

SANTOS, Joel Rufino. Quando eu voltei, tive uma surpresa. Rio de Janeiro: Rocco, 2000.

SOUZA, Elizeu Clementino de. $\mathbf{0}$ conhecimento de si: estágio e narrativas de formação de professores. Rio de Janeiro: DP\&A; Salvador: UNEB, 2006.

WALACHAI. Direção: Rejane Zilles. Porto Alegre: Zilles Produções, 2013. 1DVD (84 min).

Recebido em: 29.09.2019 Revisado em: 20.03.2020 Aprovado em: 26.03.2020

Rosvita Kolb Bernardes é Doutora em Educação pela Universidade Estadual de Campinas. Mestre em Educação pela Pontifícia Universidade Católica de São Paulo. Professora da Escola de Belas Artes da Universidade Federal de Minas Gerais. Desenvolve pesquisa, extensão e ensino entre Arte e Educação, Infância, Formação Estética Docente, Narrativas Autobiográficas. E-mail: rosvitakolb@gmail.com 